\title{
Estágios evolutivos da Bacia do Camaquã (RS)
}

\author{
Development stages of the Camaquã Basin
}

\author{
Paulo Sérgio Gomes Paim¹, Farid Chemale Junior ${ }^{2}$ e Wilson Wildner ${ }^{3,1}$ \\ ${ }^{1}$ Universidade do Vale do Rio dos Sinos (UNISINOS) \\ ${ }^{2}$ Universidade de Brasília (UNB) \\ ${ }^{3}$ Companhia de Pesquisas de Recursos Minerais (CPRM)
}

\begin{abstract}
Resumo
Este capítulo faz uma revisão de conceitos e hipóteses apresentados anteriormente acerca da Bacia do Camaquã (região central do Rio Grande do Sul) à luz de uma série de evidências, dados e estudos realizados desde então, incluindo aí um grande número de estudos geocronológicos. A Bacia do Camaquã continua sendo vista como o resultado da superimposição entre 630 e $510 \mathrm{Ma}$ de diversas bacias independentes, mas sucessivas em um mesmo locus deposicional. Independentes, mas vinculadas aos estágios finais da orogenia Brasiliana no Estado do Rio Grande do Sul, evoluindo desde bacias tardi- (bacias de retro-arco de antepaís Maricá e Transcorrentes Bom Jardim Leste e Oeste) até pós-orogênicas (riftes Santa Bárbara Oeste e Leste e Rifte Guaritas). Cada ciclo tectono-sedimentar (exceto o basal) se caracterizou por um vulcanismo basal que evoluiu desde magmas toleiticos e calcialcalinos alto-K a shoshoníticos (Evento Bom Jardim), evoluindo para um vulcanismo bimodal de afinidade alcalina sódica (Evento Acampamento Velho) e culminando com magmas mantélicos básicos alcalinos extraídos da base da crosta recémformada (Evento Rodeio velho). A sucessão sedimentar que se intercalou e sucedeu cada um destes grandes episódios vulcânicos se caracterizou pelo contex to dominantemente marinho na base (Alogrupo Maricá), passando por lacustre profundo com leques de borda associados (Alogrupo Bom Jardim), evoluindo para lacustre raso com deltas e leques (Alogrupo Santa Bárbara), e culminando com fácies lacustres rasas, aluviais e eólicas (Alogrupo Guaritas).
\end{abstract}

Palavras-chave: Evolução geológica, Tectônica, Estratigrafia, Bacia do Camaquã, Rio Grande do Sul.

\begin{abstract}
This chapter presents a revision of concepts and hypotheses previously presented about the evolution of the Camaquã Basin, central portion of the Rio Grande do Sul State (Southernmost Brazil). This review was based on a large number of new pieces of evidence, data and studies performed since earlier publication, including a large number of radiometric, high-quality geochronological data. The Camaqua Basin is still seen as the result of the superimposition between 630 and 510 Ma of a series of independent, but successive basins in the same locus. These basins represent the final stages of the Brasiliano Orogeny in the Rio Grande do Sul State and encompass an evolution from tardi- (Maricá Retroarc Foreland Basin and Western and Eastern Bom Jardim Strike-Slip basins) to post-orogenic (Western and Eastern Santa Bárbara rifts and Guaritas Rifte) settings. Any tectono-sedimentary cycle (except the basal one) comprise an early volcanism that has evolved throughout the evolution of the entire Camaquã Basin from tholeiitic and calci-alkaline, high-K to shoshonitic (Bom Jardim Event), through bimodal, alkaline (Acampamento Velho Event) to mantle derived, basic magmas derived from the base of the just formed continental crust (Rodeio Velho Event). The sedimentary successions that intercalate and cover the volcanic rocks has evolved from dominantly marine strata at the base (Maricá Allogroup) through deep- (Bom Jardim Allogroup) to shallow- (Santa Bárbara Allogroup) lacustrine facies associated with fan-deltas and axial braid-plain deltas, to shallow-lacustrine, deltaic and eolian deposits (Guaritas Allogroup).
\end{abstract}

Keywords: Geological evolution, Tectonics, Stratigraphy, Camaquã basin, Rio Grande do Sul State.

\footnotetext{
* ppaim@unisinos.br

Recebido: 08/05/2014 Aceito: 08/05/2014
} 


\section{Introdução}

A s primeiras investigações na Bacia do Camaquã (BC) datam do início do século XX (e.g. Carvalho, 1932), com os principais traços da estratigrafia estabelecidos ao longo do século XX. Uma reavaliação dos trabalhos prévios à luz de novos dados e conceitos (Paim et al. 2000) apresentou uma síntese sobre a evolução da Bacia do Camaquã sob a ótica de ciclos tectono-sedimentares superpostos em um mesmo locus deposicional.

Desde então, um significativo número de estudiosos se utilizaram de novas informações e abordagens para aprofundar o conhecimento sobre a bacia, testando, refinando, confirmando e/ou alterando hipóteses prévias. Esse capítulo apresenta a atual visão dos autores sobre a evolução tectono-vulcano-sedimentar da BC enraizada em conceitos testados, e parcialmente alterados à luz destas novas evidências. Pelos motivos expostos em 2000, e apesar de não ter sido aceito de forma ampla, optou-se por manter o uso de unidades aloestratigráficas. De qualquer modo, o mesmo nome pode ser adaptado a uma unidade litoestratigráfica tendo-se em mente que esta foi definida por suas discordâncias limítrofes, o que lhes atribui forte componente temporal, e não apenas por sua natureza litológica, que muitas vezes se repete em sucessivas unidades estratigráficas

\section{Contexto geológico}

A BC abarca uma sequência vulcano-sedimentar que aflora no Escudo Sul-riograndense e depositou-se nas fases tardi- a pós-colisionais do Ciclo Brasiliano do Cinturão Dom Feliciano (e.g. Fragoso-César, 1984; Chemale Jr. et al., 1995; Paim et al., 2000; Hartmann et al., 2008). Esta bacia molássica é uma das mais bem preservadas do mundo, sem deformação plástica ou metamorfismo. Com orientação NE-SW, a BC é margeada pelos cinturões Tijucas e Dom Feliciano (leste) e posicionada sobre o Terreno São Gabriel e Craton Rio de La Plata, a oeste (Fig. 1). No primeiro dominam gnaisses granodioríticos a tonalíticos, rochas metavulcano-sedimentares e ultramáficas remanescentes de assoalho oceânico, postulados como complexos derivados diretamente do manto e correspondendo a uma zona de acresção de crosta juvenil (Babinski et al., 1996). O segundo inclui as rochas paleoproterozóicas do Complexo Granulítico Santa Maria Chico (Hartmann et al., 1999; Soliani et al., 2000).

É mantida a idéia da BC representar um locus deposicional que recorda quatro pulsos tectono-vulcanosedimentares consecutivos (Paim et al. 2000), vinculados a diferentes ambientes tectônicos com distintas assinaturas vulcânicas, cujos registros estão limitados por discordâncias angulares (alogrupos) - Fig. 2. A sucessão está distribuída em cinco sub-bacias, compartimentos atuais que contém parte do preenchimento da BC e estão limitados dos demais por feições estruturais maiores, onde o embasamento encontra-se parcial ou totalmente exposto (sub-bacias Boicí-Piquiri, Guaritas, Santa Bárbara, Ramada e Taquarembó - Fig. 1). O termo bacia é usado para designar uma depressão onde se acumulou o registro de um episódio tectônico. Assim, a BC armazena

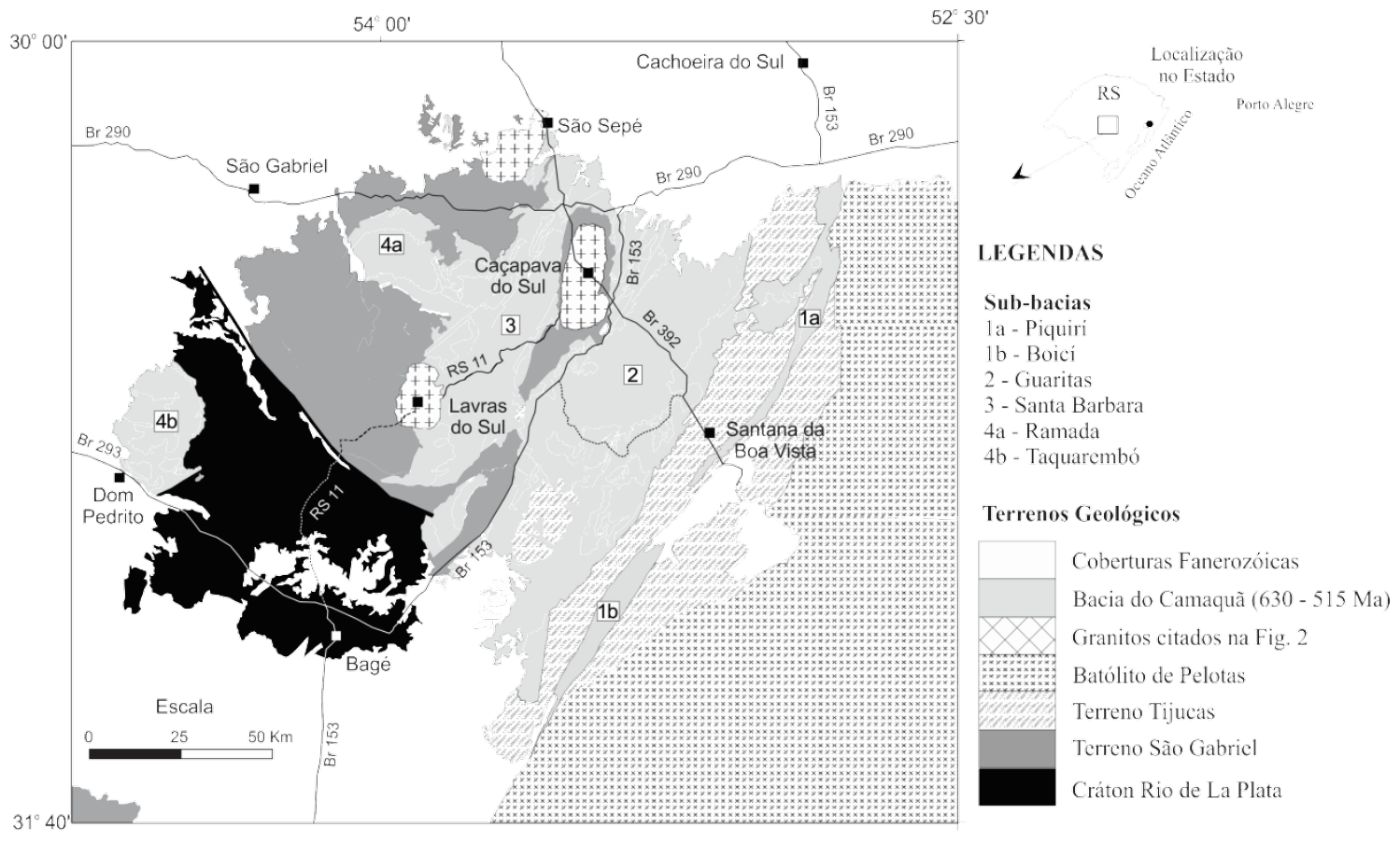

Figura 1 - Contexto geológico da Bacia do Camaquã no Estado do Rio Grande do Sul. Adaptado de Chemale Jr. (2000). Base cartográfica: Projeto "Cartas Metalogenéticas do Brasil” (Folhas de Porto Alegre, Cachoeira do Sul, Bagé e São Gabriel) executado pela CPRM. 


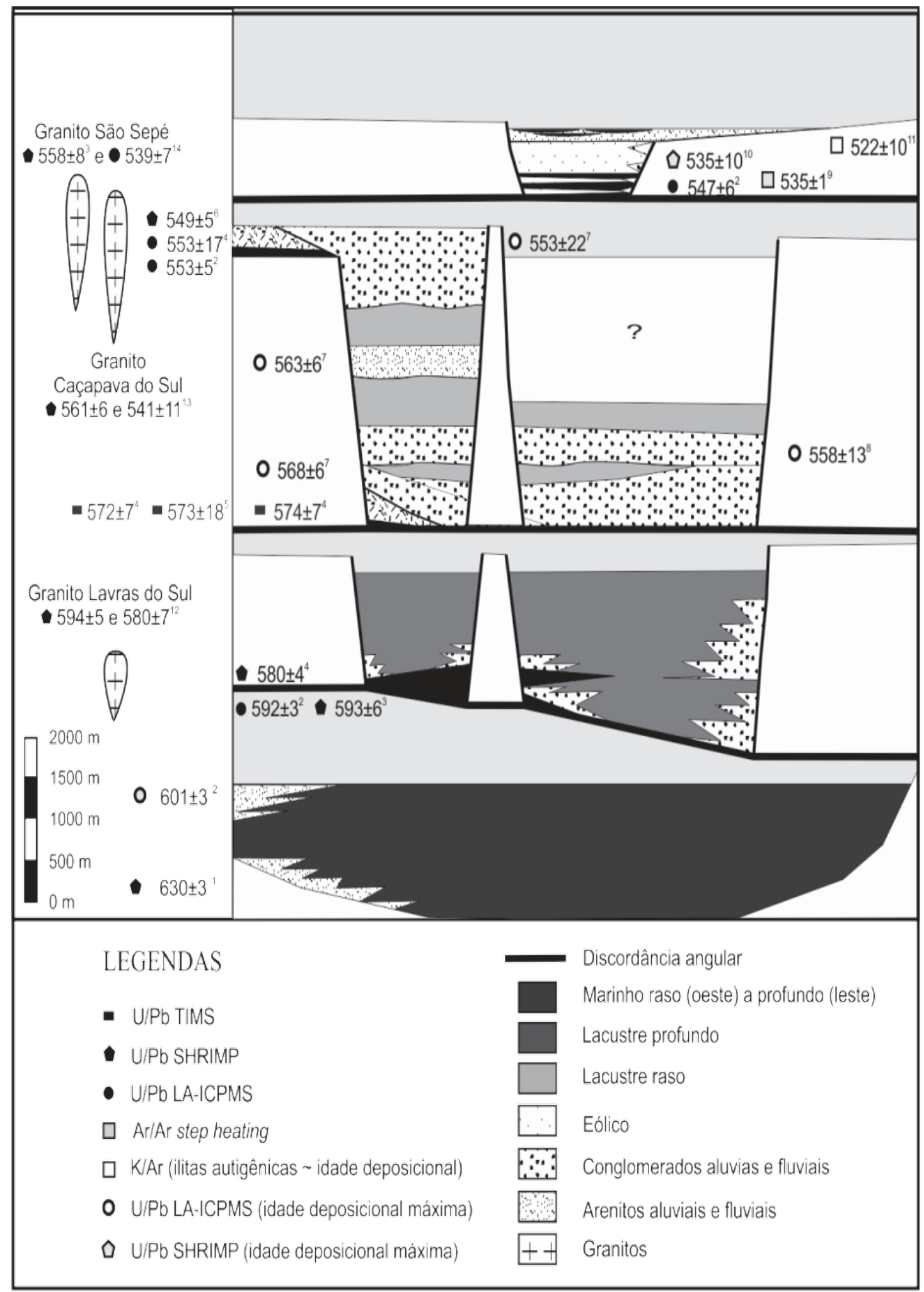

Figura 2- Evolução tectono-sedimentar da BC (adaptado de Paim et al. 2000 e Oliveira et al. 2014). Idades de referência: (1) Borba et al. (2008); (2) Almeida et al. (2012); (3) Remus et al. (1999), (4) Janikian et al., 2012; (5) Chemale, 2000; (6) Sommer et al. (2005); (7) Oliveira et al (2014); (8) Bicca et al. (2013); (9)Almeida (2005); (10) Hartmann et al. (2008); (11) Maraschin et al. 2010; (12) Remus et al. 2000; (13) Leite et al. 1998; e (14) Gastal et al. 2010 
a sobreposição parcial ou total do registro das bacias (1) de antepaís de retroarco Maricá (Alogrupo Maricá - AM); (2) transcorrentes (strike-slip) Bom Jardim Oeste e Leste (Alogrupo Bom Jardim - ABJ); (3) riftes Santa Bárbara Oeste e Leste (Alogrupo Santa Bárbara - ASB) e (4) Rifte Guaritas (Alogrupo Guaritas - AG).

No geral, a sucessão registra uma deformação decrescente da base para o topo (Paim et al. 2000), com as unidades mais antigas (alogrupos Maricá e Bom Jardim) apresentando dobras moderadamente apertadas vinculadas a falhas transcorrentes, inversas e de empurrão. Isto indica ambiente dúctil-rúptil em contexto compressivo ou transpressivo. A discordância angular que limita essas duas unidades, assim como a discordância angular suave que limita as sequencias que compõem o ABJ na Sub-bacia Piquirí, indica que a tectônica compressiva / transcorrente não apenas deformou como controlou a origem e evolução dos estágios iniciais da BC. Já os alogrupos mais jovens (Santa Bárbara e Guaritas) foram depositados em ambiente continental sob a influência do final da tectônica transcorrente sinistral (Chemale Jr., 2000) ou estágios finais da tectônica de escape lateral do Cinturão Dom Feliciano (Tommasi et al., 1994) durante a aglutinação final do Gondwana Ocidental em ambiente transtracional (Chemale Jr., 1993; Paim et al. 2000). Essas unidades possuem dobras de araste amplas e suaves vinculadas a falhas transcorrentes e normais geradas em ambiente rúptil transtracional. Essa tendência também se reflete nos ambientes deposicionais, com uma gradativa continentalização e interiorização da BC, desde um contexto marinho (AM) que passa a lacustre profundo (ABJ), fluvial e lacustre raso (ASB) e culmina com eólico, aluvial e lacustre raso (AG).

Diferenciam-se três grandes episódios magmáticos vinculados aos estágios tardi a pós-colisionais da Orogenia Brasiliana (Wildner et al., 2002, Lima et al., 2007, Sommer et al., 2011). Inicia com uma série calcialcalina alto-K a shoshonítica (vulcanismo Hilário) seguido por um magmatismo alcalino a peralcalino sódico, indicativo de uma crescente estabilização de crosta (vulcanismo Acampamento Velho), e é por fim substituído por magmas mantélicos básicos alcalinos (vulcanismo Rodeio Velho) extraídos da base da crosta recém-formada durante uma última fase distensiva, caracterizando assim o fim da sedimentação molássica (Wildner et al., 1997).

\section{Estágios evolutivos}

\subsection{As Bacias Tardi-Orogênicas}

\subsubsection{Bacia de retro-arco de antepaís Maricá (Alo- grupo Maricá)}

O Alogrupo Maricá (Paim et al., 2000) é a unidade mais antiga e deformada da BC, com dobras suaves a moderadas vinculadas a falhas transcorrentes, de em- purrão e inversas. É limitado por uma não conformidade (base) e por uma suave discordância angular (topo). É correlato à Formação Maricá de Leinz (1941) e Ribeiro et al. (1966), na sub-bacia Ramada, e à porção inferior do Membro Mangueirão de Ribeiro et al. (1966), na Sub-Bacia Piquirí.

Na Sub-bacia Ramada sua base registra um hiato de várias dezenas de milhões de anos, pois recobre o terreno juvenil São Gabriel de idade 0,9 a 0,7 Ga (Chemale Jr. et al , 1995; Babinski et al , 1996; Hartmann et al, 2011). Entretanto, esse substrato nada contribuiu como fonte, pois seus clastos registram a erosão de um terreno granito-gnáissico paleoproterozoico (Borba, 2006; Borba et al. 2008). Ao extrapolar sua ocorrência para leste faltam dados para correlações, pois não existe continuidade física entre os intervalos expostos nos distintos blocos estruturais e, por vezes (e.g. centro e leste da Sub-bacia Guaritas e Sub-bacia Piquirí/Arroio Boicí), inexistem dados geocronológicos que comprovem as correlações. No entanto, alguns pontos (fonte, associação de fácies, paleocorrentes e ausência de vulcanismo expressivo) sugerem que o AM restringe-se à Sub-bacia Ramada e à porção inferior da Sub-bacia Piquirí.

Na Sub-bacia Ramada, a seção exposta registra um ciclo transgressivo-regressivo (ciclo T-R) de cerca de $1700 \mathrm{~m}$ de espessura (Borba et al., 2008) composto por uma sucessão inferior fluvial entrelaçada, uma intermediária marinha rasa e uma superior flúvio-deltaica (Paim, 1994; Borba et al., 2008). Esses intervalos são correlatos às formações Passo da Promessa, São Rafael e Arroio América de Pelosi \& Fragoso-César (2003). As paleocorrentes aluviais são para ESE (Paim, 1994; Paim et al., 2000; Borba, 2006). Na Sub-bacia Piquirí essa unidade compreende um ciclo T-R com cerca de 2000 $\mathrm{m}$ de espesura que também apresenta paleocorrentes para SE (Sequência I de Paim et al., 2003). Inclui uma delgada sucessão basal ligada a leques deltaicos seguida de uma seção turbidítica grano-decrescente que inverte este padrão para o topo. Os ruditos são correlatos à Formação Passo da Promessa e a seção turbidítica à Formação São Rafael.

Evidências de um vulcanismo ácido foram reportadas (Leites et al., 1990; Wildner et al., 2002; Borba, 2006; Borba et al., 2008; Almeida et al., 2012), mas necessitam ainda de estudos mais pormenorizados. Borba et al. (2008) dataram zircões de seixos de rochas piroclásticas da porção superior desta unidade cuja idade (630.2 \pm 3.4 Ma) representaria a deposição de sua porção inferior/ média. Almeida et al. (2012) analisaram zircões detríticos que apontaram uma idade máxima de deposição de 601 \pm 13 Ma para o topo dessa unidade. Assume-se, com a devida cautela, um intervalo entre 630 e 600 Ma para a deposição desta unidade.

Mantém-se a interpretação de uma bacia de retro -arco de antepaís vinculada ao estágio tardi-orogênico do Cinturão Dom Feliciano (Chemale Jr., 1993, Gresse et al , 1996; Paim et al, 2000). A borda cratônica estaria 
a oeste da Sub-bacia Ramada enquanto sua margem ativa, mais profunda, se situaria à leste da atual Sub -bacia Piquirí. Essa margem ativa foi soerguida e seu registro preservado na forma de seixos a matacões de arenitos incorporados à base do $\mathrm{ABJ}$ na sub-bacia Piquirí. A pequena proporção de rochas vulcânicas, de assinatura geoquímica desconhecida, em contexto de retro-arco reforça a idéia de preservação da porção mais cratônica de uma ampla bacia de antepaís. Deste progradariam sistemas fluviais entrelaçados e deltas de planície entrelaçada em direção ao depocentro da bacia, um ambiente marinho mais profundo caracterizado por turbiditos distais (thin-bedded turbidites - tbt).

\subsubsection{Bacias transcorrentes Bom Jardim Leste e Oes- te (Alogrupo Bom Jardim)}

O Alogrupo Bom Jardim (Paim et al., 2000) abrange uma sucessão vulcano-sedimentar limitada por discordâncias angulares, de natureza suave, na base, e suave a acentuada no topo. Inclui os membros Vargas e Mangueirão de Ribeiro et al. (1966) e a Formação Hilário de Ribeiro \& Fantinel (1978). Essa unidade possui atributos genéricos úteis a correlação quando dados geocronológicos confiáveis inexistam e a correlacao física seja impossível. Por exemplo, a associação física e genética de ruditos proximais e tbt distais, os primeiros sempre supridos pelo embasamento local e/ou de vulcânicas coevas e restritos as proximidades dos altos estruturais que limitam as sub-bacias Santa Bárbara, Guaritas e Piquirí (Paim, 1994; Paim et al., 2003; Paim et al., 2000).

O ABJ registra deposição siliciclástica e vulcanoclástica, fluxos piroclásticos e de lava, e intrusões hipabissais. Os componentes vulcânicos são dominantes na porção sudoeste da Sub-bacia Santa Bárbara, arredores de Lavras do Sul. Mas diminuem radialmente, com uma gradativa substituição das lavas por rochas piroclásticas, vulcanoclásticas e siliciclásticas, nesta ordem, no sentido norte, leste e sudeste. Assim, passam a se manifestar como intercalações vulcano-sedimentares a leste do Granito Caçapava (Bom Jardim e Cerro dos Martins), a sudeste de São Sepé (Passo do Salsinho) e na base do Platô da Ramada, tornando-se ausentes nas porções centro e leste da Sub-bacia Guaritas e na Sub-bacia Piquirí/Arroio Boicí. Na Sub-bacia Guaritas, essa unidade registra um ciclo T-R com cerca de $1500 \mathrm{~m}$ de espessura (ou 3600 $\mathrm{m}$, segundo Janikian et al, 2003) de rochas siliciclásticas composto por uma seção rudítica basal, uma espessa seção de tbt intermediária, ambas correlatas a Formação Cerro da Angélica de Janikian et al (2003), e turbiditos arenosos no topo, esses equivalentes a Formação Picada das Graças desses autores que inclui na sua base um segundo intervalo conglomerático. Os conglomerados e tbt estão bem representados nas regiões de Bom Jardim e Cerro dos Martins enquanto os tbt e turbiditos arenosos estão bem preservados no furo CQP-03-RS e na região das Minas do Camaquã (Membro Mangueirão e Arenito
Inferior na estratigráfica local). Na Sub-bacia Piquirí o episódio de deformação, e posterior erosão, registrado no limite entre o AM e ABJ incluiu um processo autofágico (Fragoso-César et al. 1984) no qual seixos a matacões bem arredondados de arenitos, derivados do soerguimento do AM, foram incorporados a base da sequência basal do ABJ. As duas unidades posteriores (sequências II e III de Paim et al., 2003) foram vinculadas ao ABJ e incluem dois ciclos T-R (2000 m de espessura) correlatos aos episódios deposicionais registrados nas formações Cerro da Angélica e Picada das Graças (Janikian et al, 2003).

O vulcanismo Hilário possui composição dominante intermediária e assinatura calcialcalina alto-K a shoshonítica (Nardi e Lima, 1985; Lima, 1995; Nardi, 1986; Nardi \& Lima, 2000; Lima et al., 2007; Almeida et al , 2012). Inclui lavas de olivina basaltos porfiríticos até riolíticas, com domínio dos termos intermediários. Os segmentos hipabissais e plutono-vulcânicos estão representados por parte do Complexo Granítico de Lavras do Sul (Nardi e Lima, 1985), intrusões subvulcânicas de monzonitos, quartzo-monzonitos e leucodioritos cumuláticos (Lima, Sommer e Nardi, 2007), domos de lamprófiros espessartíticos e stocks graníticos (e.g. Monzogranito Santo Antônio e Santa Rita). Na região de São Sepé, Porcher et al. (1995) descrevem basaltos, basalto-andesitos e andesitos cuja composição indica afinidades intermediárias entre as séries calci-alcalina alto-K e shoshonítica, ambas relacionadas a arcos vulcânicos orogênicos desenvolvidos em margens continentais. Descrevem também rochas piroclásticas vulcanoclásticas e lavas andesíticas vinculadas a acumulações subaéreas geradas por processos de queda e fluxo. O conjunto de estruturas e texturas apontam para ambiente vulcânico continental de moderada taxa de explosividade, compondo um estrato-vulcão do tipo estromboliano, onde a presença de corpos d'água ocorre de forma esporádica.

Dados U-Pb e Ar-Ar de andesitos indicam idades entre 585 e 590 Ma (Janikian et al., 2008). Idades U-Pb SHRIMP de zircões em andesitos variam entre $593 \pm 6$ Ma (Remus et al., 1999) e 580 $\pm 3,6$ Ma (Janikian et al., 2012). Almeida et al., (2012) obtiveram idade U-Pb de $591.8 \pm 3.0$ Ma para lamprófiros espessartíticos. Estima-se desse modo que a deposição do ABJ ocorreu entre 593 \pm 6 e $580 \pm 3,6 \mathrm{Ma}$.

Na Sub-bacia Piquirí a deformação que afetou e foi simultânea a deposição do ABJ, foi decomposta por Silveira (2012) e atribuída a tectônica direcional, em conformidade com modelos prévios (Sayeg, 1993; Oliveira \& Fernandes, 1991). Em geral, a composição local dos clastos dos conglomerados, esses sempre próximos aos altos que limitam as sub-bacias Santa Bárbara, Guaritas e Piquirí/Boicí, indica que esta unidade depositou-se em bacias menores limitadas por falhas, como proposto por Janikian et al. (2003). Isso é coerente com as paleocorrentes, dominantemente axiais a partir de ambos os extremos (Paim 1994). Foram assim delineadas duas bacias transcorrentes, uma a oeste (Bom Jardim Oeste) e 
outra a leste (Bom Jardim Leste) do Alto de Caçapava do Sul. As duas bacias transcorrentes foram associadas às fases tardi-orogênicas em um contexto de back arc, com o arco vulcânico situado junto a uma margem continental e caracterizado por magmas toleíticos e calcialcalinos alto-K a shoshoníticos. Essas bacias registram processos vulcânicos (fluxos de lavas e piroclásticos) e sedimentares (siliciclásticos e vulcanoclásticos) contemporâneos, com os primeiros dominando na região sudoeste da Sub-bacia Santa Bárbara. A sedimentação siliciclástica e vulcanoclástica coeva se deu através de leques deltaicos (aporte lateral) e deltas de planície entrelacada (fontes fluviais axiais provenientes de ambos os extremos). Esses depósitos subaéreos deltaicos gradam para lobos turbidíticos arenosos, secundários e desenvolvidos na região axial da Sub-bacia Guaritas, e para turbiditos finamente acamadados (tbt) provenientes do aporte lateral (fan-deltas) e como franja dos lobos axiais. A natureza fechada destas bacias, a ausência de fósseis e de feições sedimentares indicativas da ação de ondas e marés, e a rara presença de estruturas relacionadas à exposição subaérea, sugerem leques deltaicos e deltas de planície entrelaçada axiais adentrando lagos relativamente profundos.

\subsection{As Bacias Pós-Orogênicas}

\subsubsection{Riftes Santa Bárbara Leste e Oeste (Alogrupo Santa Bárbara)}

O Alogrupo Santa Bárbara (ASB) representa mais uma sucessão vulcano-sedimentar e engloba as formações Acampamento Velho (Ribeiro \& Fantinel, 1978) e Santa Bárbara (Robertson, 1966) e alogrupos Cerro do Bugio e Santa Bárbara (Paim et al. 2000). Preenche dois riftes (Santa Bárbara Oeste e Leste), apesar do intervalo vulcânico superior extrapolar esses limites, repousando diretamente sobre o embasamento situado a oeste. $\mathrm{O}$ ASB é limitado por discordâncias angulares expressivas e registra um episódio singular de evolução da BC (Oliveira et al. no prelo).

Os vulcanitos da Aloformação Acampamento Velho Inferior (AVI), bem expostos na Serra Santa Bárbara, são cobertos por um espesso pacote sedimentar que é seguido por outro intervalo vulcânico (Alformação Acampamento Velho Superior - AVS), similar ao basal, mas exposto nos platôs do Taquarembó e da Ramada. Os derrames e tufos ácidos da AVI recobrem uma importante discordância angular e são cobertos pelas aloformações Santa Fé Inferior e Superior, Serra dos Lanceiros e Segredo. Cada uma dessas unidades inicia com uma discordância erosiva recoberta por depósitos de rios entrelaçados que são superpostos abruptamente (superfície transgressiva) por sucessões lacustres. Diferem entre si no sentido da seção aluvial basal ser arenosa na Aloformação Serra dos Lanceiros e conglomerática nas demais, da sucessão lacustre incluir um trato regressivo no topo da Aloformação Santa Fé Superior e da Aloformação Segredo conter apenas a seção conglomerática basal. Nas sub-bacias Guaritas e Piquirí afloram apenas as aloformações basais (Santa Fé Inferior e Superior).

O vulcanismo Acampamento Velho se manifesta por depósitos efusivos (fluxos de lava) e explosivos (ignimbritos e relacionados), com domínio dos termos piroclásticos ácidos e plutônicos epizonais. Os derrames iniciam com lavas básicas (base das sucessões) que são seguidas por rochas piroclásticas e lavas riolíticas até o topo da unidade (magmatismo bimodal). Diversos autores (Wildner et al. 2002, Sommer et al. 2005, Lima et al. 2007 e Almeida et al. 2012) identificaram uma afinidade alcalina bimodal sódica. No diagrama TAS as lavas básicas classificam-se como basaltos, traquibasaltos e basalto-andesitos, próximos à linha que divide as séries subalcalinas das alcalinas, enquanto as ácidas são classificadas como traquitos e riolitos. Wildner et al. (1999) evidenciaram um trend comendítico, com teores de $\mathrm{Zr}$ cerca de 15 vezes mais elevados que os de $\mathrm{Nb}$, típico de associações de margens continentais ativas ou de ambientes pós-colisionais posicionados acima de zonas de subducção. Isso é também indicado pelas fortes anomalias negativas de $\mathrm{Nb}$-Ta (fonte mantélica única tipo EM1) sendo que as variações entre os termos metaluminosos e peralcalinos apontam distintos graus de fusão parcial. Altos teores em $\mathrm{Ba}$, em especial no Platô do Taquarembó, sugerem uma contribuição pelágica como um dos contaminantes da fonte mantélica, reforçando a hipótese de subducção litosférica ao invés de um processo de delaminação.

O intervalo sedimentar do ASB comprende arenitos e conglomerados intercalados de forma abrupta com pacotes areno-pelíticos. Em geral os ruditos e psamitos são lenticulares, bem estratificados e incluem superfícies de acresção frontal relacionadas a barras transversais com mais de $4 \mathrm{~m}$ de altura (rios entrelaçados de grande porte). A fração areno-pelítica e pelítica é composta por tbt e corpos sigmoidais de arenitos médios a grossos associados a pelitos ressecados. Essas fácies representam um trato de fácies deltaico relacionado a frente deltaica proximal (lobos sigmoidais) e distal (tbt areno-pelíticos) e prodelta (tbt pelíticos). As paleocorrentes na Sub-bacia Santa Bárbara (Paim, 1994; Paim et al. 2000; Almeida, 2005; Fambrini et al., 2006) indicam sistemas axiais e aporte lateral de ambos os bordos (ESE e NNW). O conjunto de dados indica uma bacia orientada para NNE com deltas de planície entrelaçada (axiais) e leques deltaicos (aporte lateral de ambos os bordos) progradando em lagos rasos e dispersando sua carga na forma de lobos de frente deltaica que gradam para turbiditos de frente deltaica e prodelta. Os sistemas aluviais incluiam canais entrelaçados cascalhosos (base e topo da unidade) e arenosos (meio da sucessão). Nas sub-bacias Guaritas e Piquirí as exposições são descontínuas, limitadas a pequenas áreas na região de Bom Jardim, na janela Bom Jardim (Aloformação Santa Fé Inferior e Superior = Conglomerado 
Inferior até Arenito Superior na nomenclatura local) e intervalo superior da Sub-bacia Piquirí (sequências IV e V de Paim et al. 2003). Fácies e paleocorrentes (Paim, 1994, Paim et al. 2000; Bicca, 2013) indicam leques deltaicos progradando para WNW a partir da margem SE da Sub-bacia Piquirí e, no sul, deltas de planície entrelaçada cascalhosa e arenosa progradando para NE. Ambos os sistemas colmatavam um lago raso, estando os turbiditos prodeltaicos distais bem representados na porção NW da Sub-bacia Guaritas.

Riolitos e tufos ácidos da AVI na Serra Santa Bárbara foram datados (U-Pb em zircão) em $573 \pm 18 \mathrm{Ma}$ (Chemale, 2000) e $574 \pm 7$ Ma e $572 \pm 6.5$ (Jenikian et al., 2012). As alformações Santa Fé (Inferior e Superior), Lanceiros e Segredo (seqüências I, II e III de Borba e Mizusaki 2003) possuem idades máximas de deposição de $568 \pm 6$; $563 \pm 6$ e $553 \pm 22 \mathrm{Ma}$ (Oliveira et al. no prelo). Por outro lado, zircões detríticos da Alformação Santa Fé (Inferior e Superior) indicam idade máxima de $558 \pm 13$ Ma para esta unidade nas Minas do Camaquã (Bicca, 2013; Bicca et al. 2013). Já no Platô da Ramada, basaltos andesíticos basais foram dadatos em $553 \pm 5,4$ Ma e derrames riolíticos de níveis superiores em $549 \pm$ $5 \mathrm{Ma}$ (Sommer et al., 2005). Idade similar (553 $\pm 17 \mathrm{Ma}$ ) foi encontrada (Janikian et al. 2012) para riolitos da base do Platô do Taquarembó (Fig. 2). Almeida et al. (2012) dataram andesito basáltico (U-Pb em zircão) em 553 \pm 5.4 Ma, idade similar a AVS. Assim, estima-se que o ASB acumulou-se de $574 \pm 7$ a $549 \pm 5$ Ma.

As estruturas direcionais e normais junto com as demais feições vulcano-sedimentares sugerem duas bacias rifte limitadas pelo alto de Caçapava do Sul e formadas em contexto transtracional. Nestas, leques deltaicos provenientes dos bordos e deltas de planície entrelaçada provenientes de sul colmatavam lagos rasos controlados pela moderada (arenitos e conglomerados) a acentuada (tbt) subsidência mecânica. Estas bacias registram o primeiro grande episódio vulcano-sedimentar pós-orogenico que inclui diversos episódios de reativação (aloformações). O vulcanismo bimodal associado à formação das bacias foi expressivo no bordo oeste do Rifte Santa Bárbara Oeste. Já o vulcanismo mais jovem recobre zonas mais estáveis na borda cratônica (platôs da Ramada e Taquarembó), onde seu registro foi pouco afetado pela tectônica que deformou o restante do ASB.

\subsubsection{O Rifte Guaritas (Alogrupo Guaritas)}

O Alogrupo Guaritas (Paim et al 2000) equivale a Formação Guaritas (Goñi et al. 1962) e em seus cerca de $600 \mathrm{~m}$ de espessura registra o último episódio tectonosedimentar da BC. Repousa horizontalmente, em geral, sobre uma discordância angular e inclui duas unidades limitadas por uma discordância erosiva. A Aloformação Pedra Pintada (Paim et al 2000) se diferencia por expressivos depósitos eólicos e, próximo à margem $\mathrm{SE}$ do rifte, fácies aluviais. Esses estratos se intercalam na base com rochas vulcânicas do Membro Rodeio Velho (Ribeiro et al. 1966). Acima ocorre a Aloformação Varzinha (Paim et al. 2000) com fácies fluviais, lacustres e eólicas. De Ros et al. (1994) apontam que a deposição do AG ocorreu sob clima árido a semi-árido, hipótese essa apoiada pela abundância de estratos eólicos (Fragoso-César et al., 1984; Paim \& Scherer, 2002; Almeida, 2005) e natureza efêmera dos rios (Paim, 1994, 1995) e lagos (Paim, 1994).

O vulcanismo Rodeio Velho se manifesta por derrames e diques intermediários a básicos, além de diques clásticos, que se intercalam com arenitos e ruditos na base do AG. Está melhor exposto a leste da Janela Bom Jardim (Passo do Moinho e Cerro Cascavel), na sinclinal do Arroio da Porteira e no passo do Arroio Carajá. Foram descritos seis derrames vesiculares (espessura de 119 m) na sondagem CQP-01-RS (janela Bom Jardim). Na sinclinal do Arroio da Porteira ocorrem seis níveis de rochas vulcânicas intercalados com paraconglomerados e arenitos grossos a conglomeráticos de leques aluviais e, localmente, arenitos eólicos. No Cerro Cascavel os níveis vulcânicos intercalam-se com fácies eólicas e fluviais (Fallgatter et al., in press). Os derrames apresentam uma complexa estruturação interna, com estruturas de lavas subaéreas tipos corda e aa e fluxos inflados com festões e tubos de lava (Wildner et al., 1997; Lima et al., 2005; Almeida et al., 2012). A base e, sobretudo o topo dos lóbulos são intensamente vesiculados (50\% em volume) com vesículas do tipo pipes na base indicando os limites de lóbulos e sentido de fluxo. Nas regiões do Cerro Cascavel e Arroio Carajá ocorrem feições de interações entre derrames de lavas básicas e sedimentos saturados em água, desenvolvendo expressivos horizontes peperíticos (e.g. Fallgatter et al., in press). As texturas e estruturas apresentam um comportamento reomórfico similar aquelas desenvolvidas em toleíitos hawaiianos do tipo pahoehoe.

A Aloformação Pedra Pintada (Paim et al. 2000) ultrapassa $100 \mathrm{~m}$ de espessura e está descrita em detalhe em trabalhos anteriores (Paim 1994, Paim \& Scherer 2002, Scherer et al. 2003 e Almeida 2005). Envolve a superposição de paleoergs formados por campos de dunas barcanas simples e compostas, e interdunas secos, nas porções central e ocidental da bacia, e lençóis arenosos (eólicos) intercalados com depósitos de fluxos de detritos, na margem oriental (borda ativa do rifte). Separando os paleoergs, e refletindo mudanças climáticas, tem-se a formação de supersuperfícies de inundação, delineadas por superfícies de Stokes e preservação parcial da morfologia das dunas, e subsequente recobrimento por fácies lacustres rasas que incluem depósitos deltaicos decimétricos retrabalhados por ondas e eventualmente dissecados. Na margem ativa, de forma coeva a essas inundações, formavam-se leques aluviais e deltaicos (bajada), com ruditos e arenitos de planície deltaica, turbiditos e pelitos de águas rasas e depósitos de fluxos de detritos. O assoreamento dos lagos efêmeros por campos de dunas marca o retorno as condições áridas, 
dando início a formação de um novo erg. As fácies eólicas e aluviais marginais são correlatas às formações Pedra Pintada e Pedra das Torrinhas de Almeida et al. (2009), respectivamente. Como já apontado (Paim 1994, Paim et al., 2000, Paim \& Scherer, 2002; 2005) os paleoventos seguiam um regime unidirecional para NNE.

Acima de uma discordância erosiva ocorre a Aloformação Varzinha (Paim et al. 2000). Esta unidade, comparável a Formação Serra do Apertado (Almeida et al. 2009), é também atribuída ao estágio pós-rifte visto que sua deposição extrapolou os limites do rifte, recobrindo o embasamento exposto no alto de Santana da Boa Vista (Rincão dos Mouras) e os alogrupos Bom Jardim e Santa Bárbara na Sub-bacia Piquirí. Essa unidade registra um sistema de leques aluviais provenientes de ESE que é truncado próximo ao eixo do rifte Guaritas por um sistema fluvial tronco dirigido para SSW (De Ros \& Paim, 1992; Paim, 1994), Esse sistema tronco é concordante com aquele descrito por Almeida (2005) que, no entanto, o associa a sua unidade basal (Formação Guarda Velha). Outro ponto relevante é a recorrência de fácies eólicas, similares àquelas contidas na unidade precedente, mas agora associadas a um regime de ventos unidirecional dirigido para SSW. Essas foram também descritas por Almeida (2005) que, no entanto, as vincula a uma unidade que considera mais antiga (Formação Pedra da Arara). Por fim, um aumento na taxa de subsidência leva a substituição dos leques aluviais e fluvial tronco por leques deltaicos, a leste, e deltas de planície entrelaçada na borda oeste.

Basaltos alcalinos da base da seção foram datados em $547 \pm 6,3 \mathrm{Ma}$ (U - Pb em zircões) por Almeida et al. (2012). Almeida (2005) datou em $535 \pm 1$ (Ar-Ar step heating) rochas correlatas. Hartman et al (2008) encontrou uma idade máxima de deposição de $535 \pm 10 \mathrm{Ma}(\mathrm{U}$ - Pb em zircão detrítico) para a Aloformação Varzinha. Ilitas autigênicas de arenitos eólicos da Aloformação Pedra Pintada datadas pelo método $\mathrm{K}-\mathrm{Ar}$ indicam idade deposicional mínima de $522 \pm 10$ (Maraschin et al., 2010). Tendo em vista que de 500 a 470 Ma processos mesodiagenéticos já operavam na Aloformação Pedra Pintada (Maraschin et al., 2010) adota-se para o início do rifte e do vulcanismo Rodeio Velho a idade de $547 \mathrm{Ma}$, com o vulcanismo estendendo-se até $535 \mathrm{Ma}$. A idade da Aloformação Pedra Pintada é atribuída ao intervalo entre 535 e 522 Ma. E para a Alformação Varzinha adota-se uma idade entre 520 e $510 \mathrm{Ma}$.

De acordo com Wildner et al. (1997) o magmatismo Rodeio Velho sinaliza o início da inversão da BC e final da sedimentação molássica. Cessada a fase de subducção e participação de crosta no armazenamento e geração de magmas, o magmatismo Rodeio Velho registra uma nova fase distensiva, com extração de magmas mantélicos básicos alcalinos da base da crosta recém-formada. Considerando que a associação vulcano-sedimentar está restrita ao rifte e a seção superior extrapola tais limites, considera-se que o AG inclui as fases sin-e pós-rifte (Almeida et al. 2009) de um rifte transtensional de orientação N40E (Chemale Jr., 1993; Borba, 2006; Bicca et al., 2013; Oliveira et al., no prelo). A sucessão inicia com derrames que se intercalam e são recobertos por depósitos aluviais, junto a borda ativa, e eólicos, no restante do rifte, durante a fase de subsidência mecânica acelerada (sin-rifte), sob condições de balanço hídrico negativo. Esse regime hidrológico se reflete no domínio de fácies eólicas (ao invés de lacustre) e expressiva subsidência mecânica na preservação de uma espessa sucessão eólica pontuada por episódicas emersões do nível freático. Uma mudança climática, revelada pela mudança no regime hidrológico (agora positivo) e na direção dos paleoventos, e o extravasamento do rifte como locus deposicional representam a fase pós-rifte, com a subsidência térmica passando a controlar a acumulação e preservação dos estratos.

\section{Considerações finais}

Alguns desafios, em especial na cronologia do vulcanismo e das fontes sedimentares, foram enfrentados com a ampliação e modernização da estrutura laboratorial instalada no país e aumento no número de pesquisadores envolvidos. Contribuições importantes derivaram também de outras abordagens (geologia estrutural e geofísica), mas ainda não na dimensão necessária. Trabalhos mais tradicionais de sedimentologia trouxeram a tona outras possibilidades de interpretações para certas unidades, em especial as superiores (e.g. Marconato, 2010). A estratigrafia proposta por Paim et al. (2000) foi, em seus grandes traços, testada e adotada pela maioria dos pesquisadores que continuaram a trabalhar na área. O conjunto de informações subsidiou a proposição de um modelo tectono-sedimentar evolutivo que converge com a maioria ao considerar a BC como resultado da superposição de bacias no decorrer das fases finais do Ciclo Brasiliano sob domínio de esforços compressivos / transpressivos de início e distensivo / transtrativos no final. Investigações geofísicas mais amplas, análises estruturais amarradas a estratigrafia e uma melhor definição das idades, em especial da base e topo, são ainda necessárias. A estratigrafia isotópica pode se constituir em nova ferramenta de correlação entre blocos estruturais desconectos.

\section{Referências}

Almeida, R.P. (2005) Tectônica e Sedimentação do Ediacarano ao Ordoviciano: Exemplos do Supergrupo camaquã (RS) e do Grupo Caacupé (Paraguai Oriental). Tese de Doutorado, IG-USP, 203 p.

Almeida R.P. et al. (2009) Evolution of a rift basin 
dominated by sub aerial deposits: The Guaritas Rift, Early Cambrian, Southern Brazil. Sedimentary Geology 217, 30-51

Almeida, D.P.M. et al. (2012) Late to Post-Orogenic Brasiliano-Pan-African Volcano-Sedimentary Basins in the Dom Feliciano Belt, Southernmost Brazil, in: Al-Juboury, A.I. (Ed.), Petrology - New Perspectives and Applications, pp. 73-135.

Babinski, M. et al. (1996) Juvenile accretion at 750-700 Ma in southern Brazil. Geology 24, 439-442.

Bicca, M.M. (2013) Tectônica e Proveniência do Grupo Santa Bárbara, Região de Minas do Camaquã - RS. Dissertação de Mestrado, IG-UFRGS, 130 p.

Bicca, M.M. et al. (2013) Tectonic evolution and provenance of the Santa Bárbara Group, Camaquã Mines region, Rio Grande do Sul, Brazil. Journal of South American Earth Sciences 48, 173-192.

Borba, A.W. (2006) Evolução geológica da "Bacia do Camaquã" (Neoproterozóico e Paleozóico Inferior do Escudo Sul-Riograndense, RS, Brasil: uma visão com base na integração de ferramentas de estratigrafia, petrografia e geologia isotópica. Tese de Doutorado, Porto Alegre, UFRGS/IG, 110p.

Borba, A.W. \& Mizusaki, A.M.P. (2003) Santa Bárbara Formation (Caçapava do Sul, southern Brazil): depositional sequences and evolution of an Early Paleozoic post-collisional basin. Journal of South American Earth Sciences 16 (5), 365-380.

Borba, A.W. et al. (2008) U-Pb zircon and 40Ar-39Ar K-feldspar dating of syn-sedimentary volcanism of the Neoproterozoic Maricá Formation: constraining the age of foreland basin inception and inversion in the Camaquã Basin of southern Brazil. Basin Research 20, 359-375.

Carvalho, P.F. (1932) Reconhecimento geológico no Estado do Rio Grande do Sul. Boletim do Serviço Geológico e Mineralógico do Brasil 66, 1-72.

Chemale Jr., F. (2000) Evolução geológica do Escudo Sul-rio-grandense, in: Holz, M., De Ros, L.F. (Eds), Geologia do RS. CIGO/UFRGS, Porto Alegre, pp. 13-52.

Chemale Jr., F. et al. (1995) Stratigraphy and Tectonism of Precambrian to Early Paleozoic Units. XVIII Acta Geologica Leopoldensia, 42, 5-117.

De Ros, L.F. et al. (1994) The role of detrital composition and climate on the diagenetic evolution of continental molasses: evidence from the Cambro-Ordovician Guaritas sequence, southern Brazil. Sedimentary Geology 92, 197-228.

Fallgatter, C. et al. (no prelo) The early fill of a rift basin dominated by the interaction of lava flows and aeolian dunes: The Guaritas Rift, Southern Brazil. No prelo.

Fambrini, G.L. et al. (2006) Estratigrafia e evolução paleogeográfica do Grupo Santa Bárbara (Eoediacarano) na Sub-bacia Camaquã Ocidental, Rio grande do sul, Brasil. Revista Brasileira de Geociências 36 (3): 550-565.

Fragoso-César, A.R.S. et al. (1984) A antefossa molássica do cinturão Dom Feliciano no escudo do Rio Grande do Sul. Congresso Brasileiro de Geologia, 33, 3272-3283.

Gastal, M.C.P. et al. (2010) U-Pb and Pb-Pb zircon ages of Neoproterozoic-Eopaleozoic granites from the western portion of the southern Brazilian Shield, in: South American Symposium on Isotopic Geology. Short Papers VII SSAGI, Brasília.

Goñi, J. et al. (1962) Estratigrafía e Geologia Económica do Pré-Cambriano e Eo-Paleozóico Uruguaio e Sul-Riograndense. Avulso da Escola de Geologia, UFRGS (3):1-105.

Gresse, P.G., et al. (1996) Late- to post-orogenic basins of the Pan-African-Brasiliano-collision orogen in Southern Africa and Southern Brazil. Basin Research 8 (2) 157-171.

Hartmann et al. (1999) Deepest exposed crust of Brazil - SHRIMP establishes three events. Geology, 27: 947-950

Hartmann, L.A. et al. (2008) Detrital Zircon U-Pb Age Data and Precambrian Provenance of the Paleozoic Guaritas Formation, Southern Brazilian Shield. International Geology Review 50, 364-374.

Hartmann, L.A. et al. (2011) Time frame of 753-680 Ma juvenile accretion during the São Gabriel orogeny southern Brazilian Shield. Gondwana Research 19, 84-99.

Janikian, L. et al. (2003) Redefinição do Grupo Bom Jardim (Neoproterozóico III) em sua áreatipo: litoestratigrafia, evolução paleoambiental e contexto tectônico. Revista Brasileira de Geociências 33(4): 349-362.

Janikian, L. et al. (2008). The continental record of 
Ediacaran volcano-sedimentary successions in southern Brazil and their global implications. Terra Nova, (20), 259-266.

Janikian, L. et al. (2012) Ages (U-Pb SHRIMP and LA ICPMS) and stratigraphic evolution of the Neoproterozoic volcano-sedimentary successions from the extensional Camaquã Basin, Southern Brazil. Gondwana Research 21, 466-482.

Leinz, V. et al. (1941) Mapa Geológico CaçapavaLavras. Boletim 90, Secretaria da Agricultura, Indústria e Comércio, RS.

Leite, J.A.D. et al. (1998) SHRIMP U/Pb zircon geochronology of Neoproterozoic juvenile and crustal-reworked terrains in southernmost Brazil. International Geology Reviews 40, 688-705.

Leites; S.R. et al. (1990) Divisão litofaciológica da Bacia do Camaquã na Folha Passo do Salsinho, Caçapava do Sul - RS, e sua interpretação paleoambiental. Congresso Brasileiro de Geologia, 36(1), 300-312.

Lima, E. F. (1995) Petrologia das rochas vulcânicas e hipoabissais da Associação Shoshonítica de Lavras do Sul - ASLS. Tese de Doutorado, IG/UFRGS, 338 p.

Lima E. F. et al. (2007) O vulcanismo Neoproterozóico Ordoviciano no Escudo Sul-rio-grandense: os ciclos vulcânicos da Bacia do Camaquã. In: Iannuzzi R. \& Frantz J.C. (eds.) 50 Anos de Geologia. Instituto de Geociências. Contribuições. Porto Alegre, Comunicação e Identidade, p. 79-95.

Maraschin, A.J. et al. (2010) Illite authigenesis in sandstones of the Guaritas Allogroup (Early Paleozoic): Implications for the depositional age, stratigraphy and evolution of the Camaquã Basin (Southern Brazil). Journal of South American Earth Sciences 29, 400-411.

Marconato, A. (2010) A influencia da evolucao de altos estruturais em sucessoes aluviais: exemplos do Ediacarano e do Cambriano da Bacia Camaqua (RS). Dissertação de Mestrado, IG/USP, 70p.

Nardi, L., Lima, E. (1985) A associação shoshonítica de Lavras do Sul, RS. Revista Brasileira de Geociências 15, 139-146.

Oliveira, J. M. M. T. \& Fernandes, L. A. D. (1991) Estágios finais da deformação do Cinturão Dom Feliciano: tectônica e sedimentação da Formação Arroio dos Nobres. Simpósio Nacional Estudos
Tectônicos, 3, 1-4.

Oliveira, C. H. E de et al. (2014) U-Pb and Lu-Hf isotopes applied to the evolution of the late to postorogenic transtensional basins of the Dom Feliciano Belt, Brazil. Precambrian Research, 246: 240-255

Paim, P. S. G. (1994) The Guaritas Desert System (Cambro-Ordovician of Southern Brazil): An Example of A Wet Desert Depositional System. 14th International Sedimentological Congress. Recife, Abstracts p. 15

Paim, P. S. G. (1995) Alluvial Palaeogeography of the Guaritas Depositional Sequence of Southern Brazil. Spec. Publs. Inter. Ass. Sediment., 22, p. 3-16.

Paim, P. S. G., Chemale, F. \& Lopes, R. C. (2000) A Bacia do Camaquã. In: M. Holz \& L. F. De Ros (Eds) Geologia do Rio Grande do Sul, Porto Alegre, p. 231-274.

Paim, P. S. G. \& Scherer, C. M. S. (2002) Arquitetura estratigráfica de sucessões flúvio-eólicas: o exemplo do Alogrupo Guaritas na região da Pedra Pintada, Rio Grande do Sul, Brasil. In: P. S. G. Paim; U. F. Faccini; R. G. Netto (Eds) Geometria, arquitetura e heterogeneidades de corpos sedimentares - Estudo de Casos, São Leopoldo, p. 38-58.

Pelosi, A. P. M. R. \& Fragoso-Cesar, A. R. S. (2003) Proposta litoestratigráfica e considerações paleoambientais sobre o Grupo Maricá (Neoproterozóico III), Bacia do Camaquã, Rio Grande do Sul. Revista Brasileira de Geociências, 33(2):137-148.

Porcher, C. A. et al. (1995) Passo do Salsinho: folha SH.22-Y-A-I-4; Rio Grande do Sul. Programa de Levantamentos Geológicos Básicos do Brasil, Brasília, CPRM, 372 p.

Ribeiro, M. et al. (1966) Geologia da quadrícula de Caçapava do Sul, Rio Grande do Sul - Brasil. Boletim do D.N.P.M., 127, 19-231.

Ribeiro, M. \& Fantinel, L. (1978) Associações petrotectônicas do Escudo Sul-rio-grandense: I -Tabulação e distribuição das associações petrotectônicas do Rio Grande do Sul. Inheringia Série Geológica 5, 19-54.

Remus, M. D. V.; Hartmann, L. A; McNaughhton, M. J.; Fletcher, I. R. (1999) Shrimp U-Pb zircon ages of volcanism from the São Gabriel Block, southern Brazil. In: Simpósio sobre vulcanismo e ambientes associados, 1. Boletim de Resumos, p. 83. 
Remus, M.V.D. et al. (2000) The link Between Hydrothermal Epigenetic Copper Mineralization and the Caçapava Granite of Brasiliano Cycle in Southern Brazil. Journal of South American Earth Sciences 13, 191-216.

Robertson, J.F. (1966) Revision of the stratigraphy and nomenclature of rock units in the Caçapava-Lavras region. State of Rio Grande do Sul, Brazil. Notas e Estudos-IG/UFRGS 1 (2), 41-54.

Sayeg, H. S. (1993) Evolução geológica brasiliana da Bacia do Arroio Boicí, RS. Instituto de Geociências/ USP. Dissertação de Mestrado, 103 p.

Scherer, C. M. S.; Paim, P. S. G. \& Melo, M. A. (2003) Estratigrafia de alta resolução em sucessões flúvioeólicas: O Exemplo do Alogrupo Guaritas (Bacia do Camaquã) na localidade de Pedra Pintada, Rio Grande do Sul, Brasil. Anais do I Encontro sobre a Estratigrafia do Rio Grande do Sul: Escudo e Bacias, UFRGS, Porto Alegre, p. 99-104.

Silveira, D. M. (2012) Tectônica e Sedimentação na Sub-Bacia do Piquirí (Bacia do Camaquã - RS). Trabalho de Conclusão de Curso (Graduação em Geologia) - Universidade do Vale do Rio dos Sinos. $85 p$.

Sommer, C. A, et al. (2005) Potassic and lowand high-Ti mildly alkaline volcanism in the Neoproterozoic Ramada Plateau, southernmost Brazil. Journal of South American Earth Sciences 18 (3), 237-254.

Sommer, C. A. et al. (2011) Reoignimbritos e ignimbritos de alto grau do vulcanismo Acampamento Velho, RS: origem e temperatura de formação. Revista Brasileira de Geociências 41(3): 420-435.

Tommasi, A. et al. (1994) Orogen-parallel strike-slip faulting and synkinematic magmatism in the Dom Feliciano Belt, Southern Brazil. Tectonics 13, 421437.

Wildner, W. et al. (1997) Vulcanismo Neoproterozóico-Cambriano no Rio Grande do Sul: estratigrafia e aspectos texturais. Revista Terra. , v.3, p.19- 27 .

Wildner, W. et al. (2002). Volcanic cycles and setting in the Neoproterozoic III to Ordovician Camaquã Basin succession in southern Brazil: characteristic of post-collisional magmatism. Journal of Volcanic and Geothermal Research, Vol.118, pp. 261-283. 